\title{
The Reawakening of Bendamustine - Also in Breast Cancer?
}

\author{
Gunter von Minckwitz Mattea Linder Sibylle Loibl
}

German Breast Group, GBG Forschungs GmbH, Neu-Isenburg, Germany

During the last decades the treatment of breast cancer has become extremely diversified. This is not only due to the new understanding of molecular subtypes (luminal, basal, HER2 positive) but also due to an increasing armamentarium of drugs showing activity in all stages of this disease. This allows us today to treat more and more patients with metastatic disease with even 10 or more lines of different endocrine, cytotoxic, or targeted mono- or combination treatments. Whereas the main goal of treatment in metastatic breast cancer is, of course, to improve overall survival, quality of life or the time without symptoms, toxicity becomes increasingly important with advanced disease. With this, even more possibilities to control disease and symptoms without compromising quality of life by toxicities or stressful administration are warranted. Therefore we have to ask: might bendamustine provide a further possibility to treat breast cancer patients?

Bendamustine was synthesized in the former German Democratic Republic (GDR) in the 1960s. The intention was to produce a nitromustard compound that was less toxic but at least as effective as alkylating agents. This was done by relocating a nitrogen mustard group to a different position [1]. It turned out that this drug not only had features of an alkylating agent but also of a purine analogue. It shows a higher stability and causes longer-lasting DNA damage. In vitro, and now also clinically, it does not show cross resistance to other alkylating agents $[2,3]$.

It was widely used in the GDR for the treatment of lymphoid malignancies, such as non-Hodgkin's lymphoma (NHL), chronic lymphocytic leukemia (CLL), multiple myeloma, and Hodgkin's lymphoma, as well as breast cancer. However, after the reunification, it lost approval for breast cancer due to insufficient safety and efficacy data according to modern standards.

However, recently the drug has attracted significant attention due to a number of positive studies in various lymphatic malignancies. A phase III study by Rummel et al. [4] showed for bendamustine $\left(90 \mathrm{mg} / \mathrm{m}^{2}\right)$ in combination with rituximab a response rate of more than $90 \%$ and a complete remission rate of up to $47 \%$ in patients with in previously untreated indolent mantel cell lymphoma. Kahl et al. [5] demonstrated that bendamustine $120 \mathrm{mg} / \mathrm{m}^{2}$ as a single agent induced a response rate of $84 \%$ and a complete response of $32 \%$ in patients with relapsed, rituximab-refractory indolent NHL. Bendamustine showed superiority to chlorambucil in patients with CLL, which led to FDA approval in the US last year.

The degree of new evidence is, so far, much less in breast cancer. In 2005 we published the largest study on this drug, comparing CMF (cyclophosphamide, methotrexate and fluorouracil) with $\mathrm{B}$ (endamustine) MF as first-line treatment for 364 patients with metastatic breast cancer [6]. Despite a significant increase of time to progression from 6.7 to 9.2 months in favor for BMF, this study did not attract too much attention. It might be that this was because of the 'old fashioned' comparator arm, but also because it was too early for the reawakening.

More recent approaches now explored better tolerable schedules of bendamustine as monotherapy. Whereas the former dose of $150 \mathrm{mg} / \mathrm{m}^{2}$ given on 2 days of a 4-week cycle proposed by Hoeffken et al. [7] was associated with high efficacy but also much higher toxicity, Reichmann et al. [8] more recently demonstrated a better net benefit for a lower dose of $120 \mathrm{mg} / \mathrm{m}^{2}$. Comparison of efficacy between the two trials has to be done with caution because of potential differences in the study populations, the size of the studies as well as improvements in response assessment over time.

In this issue of Onkologie Steinbild et al. [9] now report on another possibility how bendamustine might be given to patients with advanced metastatic breast cancer. They conducted a phase II study on 22 patients, who have been pre-treated predominantly with anthracycline and/or taxane containing

\section{KARGER}

Fax +49761 4520714

Information@Karger.de

www.karger.com (c) 2009 S. Karger GmbH, Freiburg

Accessible online at:

www.karger.com/onk
Prof. Dr. med. Gunter von Minckwitz

GBG Forschungs GmbH

Schleussnerstr. 42

63263 Neu-Isenburg, Germany

Tel. +49610279874 10, Fax -40

minckwitz@germanbreastgroup.de 
chemotherapy regimens. They used a flat dose of $200 \mathrm{mg}$ on day 1 and 2 every 4 weeks and evaluated the response according to the RECIST criteria. They found an overall response of $16 \%$, a stable disease of $22 \%$, and thus a cancer control rate of $38 \%$ in heavily pre-treated patients with metastasized breast cancer. This response rate is slightly lower but not different in statistical terms compared with results reported for $120 \mathrm{mg} / \mathrm{m}^{2}$. Again tolerability of this schedule appears to be much better than the initial high-dose schedule. However, flat dosing appears to be easier and less buggy than dosing by body surface area (BSA). The authors also refer to studies showing that the drug preparation according to BSA does not reduce the risk of interindividual variations [10-12] and thus does neither avoid over- nor underdosing contrary to the expectation. It also demonstrates that the therapeutic window of this drug is not as narrow as what we know from other compounds.

This study demonstrates that bendamustine provides another opportunity for the treatment of patients with far advanced disease, where single-agent chemotherapy is the appropriate type of therapy. However, if we really want to establish this drug in earlier stages of disease, data on combinations with other active drugs are needed. We have recently established the dose of bendamustine when given in combination with paclitaxel, and found that both drugs can be given together without dose compromises [13]. The RiTa trial is currently continued as a phase II study using recommended doses of $70 \mathrm{mg} / \mathrm{m}^{2}$ bendamustine and $90 \mathrm{mg} / \mathrm{m}^{2}$ paclitaxel. An American group in Ohio is currently investigating the combination of bendamustine with erlotinib [14].

Unfortunately, the focus of clinical trials activities with this drug is in lymphatic diseases (29 out of 39 registered trials in the clinicaltrials.gov registry). However, as the economic life cycle of this compound has already reached its ceiling, it appears less probable that a large plan for development in breast cancer exists or will be set up based on these new and promising data. It will be up to collaborative research groups to further investigate the potential of this multi-targeted agent in the field of breast cancer.

\section{References}

1 Cheson BD: Bendamustine: rebirth of an old drug. J Clin Oncol 2009;27:1492-1501.

-2 Leoni ML, Bailey B, Reifert J, et al.: Bendamustine (Treanda) displays a distinct pattern of cytotoxicity and unique mechanistic features compared with other alkylating agents. Clin Cancer Res 2008;14: 309-317.

3 Leoni LM, Niemeyer CC, Kerfoot C, et al.: In vitro and ex vivo activity of SDX-105 (bendamustine) in drugresistant lymphoma cells. Proc Am Assoc Cancer Res 2004;45:27, abstr 1215.

4 Rummel ML, et al.: Bendamustine plus rituximab versus CHOP with indolent and mantle-cell lymphomas: the first interim results of a randomized phase III study of the StiL. Blood 2007;110:120a: abstr 385 .

5 Kahl B, et al.: Bendamustine is safe and effective in patients with rituximab-refractory, indolent B-cell non-Hodgkin's lymphoma. Blood 2007;110:406a, abstr 1351.
6 Von Minckwitz, Chernozemsky I, Sirakova L, et al.: Bendamustine prolongs progression-free survival in metastatic breast cancer (MBC): a phase III prospective, randomized, multicenter trial of bendamustine hydrochloride, methotrexate, and 5-fluorouracil (BMF) versus cyclophosphamide, methotrexate and 5-fluorouracil (CMF) as front-line treatment of MBC. Anticancer Drugs 2005;16:871-877.

7 Höffken K, Merkle K, Schönfelder M, Anger G, Brandtner M, Ridwelski K, Seeber S: Bendamustin as salvage treatment in patients with advanced progressive breast cancer. A phase II study. J Cancer Res Clin Oncol 1998;124:627-632.

8 Reichmann U, Bokemeyer C, Wallwiener D, et al.: Salvage chemotherapy for metastatic breast cancer: results of a phase II study with bendamustine. Ann Oncol 2007;18:1981-1984.

9 Steinbild S, Frost A, Häring B, Unger C, Mross K: Phase II study with 3rd- or 4th-line bendamustine (flat dose) therapy in patients with metastatic breast cancer. Onkologie 2009;32:488-492.
0 DeJongh FE, Verweij J, Loos WJ, et al.: Bodysurface area-based dosing does not increase accuracy of predicting cisplatin exposure. J Clin Oncol 2001;19:3733-3739.

11 Baker SD, Verweij J, Rowinsky EK, et al.: Role of body surface area in dosing of investigational anticancer agents in adults, 1991-2001. J Natl Cancer Inst 2002;94:1883-1888.

12 Ratain MJ: Body surface area as a basis for dosing of anticancer agents: science, myth or habit? J Clin Oncol 1998;16:2297-2298.

13 Loibl S, Murmann C, Schwedler K, et al.: Phase I dose finding study evaluating the combination of bendamustine with weekly paclitaxel in patients with pre-treated metastatic breast cancer: RiTa trial. Cancer Chemother Pharmacol 2009;63:953-958.

14 www.clinicaltrials.gov identifier: NCT00834678. 